\title{
Aerosol Effects on Clouds, Precipitation, and the Organization of Shallow Cumulus Convection
}

\author{
Huiwen Xue \\ School of Physics, Department of Atmospheric Sciences, Peking University, Beijing, China
}

GRAHAM FEINGOLD

NOAA/Earth System Research Laboratory, Boulder, Colorado

BJORN STEVENS

Department of Atmospheric and Oceanic Sciences, University of California, Los Angeles, Los Angeles, California

(Manuscript received 20 February 2007, in final form 8 June 2007)

\begin{abstract}
This study investigates the effects of aerosol on clouds, precipitation, and the organization of trade wind cumuli using large eddy simulations (LES). Results show that for this shallow-cumulus-under-stratocumulus case, cloud fraction increases with increasing aerosol as the aerosol number mixing ratio increases from 25 (domain-averaged surface precipitation rate $\sim 0.65 \mathrm{~mm} \mathrm{day}^{-1}$ ) to $100 \mathrm{mg}^{-1}$ (negligible surface precipitation). Further increases in aerosol result in a reduction in cloud fraction. It is suggested that opposing influences of aerosol-induced suppression of precipitation and aerosol-induced enhancement of evaporation are responsible for this nonmonotonic behavior.

Under clean conditions $\left(25 \mathrm{mg}^{-1}\right)$, drizzle is shown to initiate and maintain mesoscale organization of cumulus convection. Precipitation induces downdrafts and cold pool outflow as the cumulus cell develops. At the surface, the center of the cell is characterized by a divergence field, while the edges of the cell are zones of convergence. Convergence drives the formation and development of new cloud cells, leading to a mesoscale open cellular structure. These zones of new cloud formation generate new precipitation zones that continue to reinforce the cellular structure. For simulations with an aerosol concentration of $100 \mathrm{mg}^{-1}$ the cloud fields do not show any cellular organization. On average, no evidence is found for aerosol effects on the lifetime of these clouds, suggesting that cloud fraction response to changes in aerosol is tied to the frequency of convection and/or cloud size.
\end{abstract}

\section{Introduction}

The effects of precipitation on shallow convection have drawn much attention in recent years because of the desire to understand and quantify aerosol effects on clouds and climate. The conceptual framework for studies of this type follows a simple train of thought: Greater aerosol loading suppresses precipitation formation, increases cloud liquid water, and leads to longer-lived clouds and larger cloud fractions. Because the albedo effect of shallow clouds is greater than their

Corresponding author address: Huiwen Xue, School of Physics, Department of Atmospheric Sciences, Peking University, Beijing 100871, China.

E-mail: hxue@pku.edu.cn greenhouse effect, this would imply a tendency for increased aerosol loading to reduce globally averaged surface temperatures, and hence offset warming associated with increased concentrations of greenhouse gases.

But clouds are a complex, and poorly understood, manifestation of their environment. In many respects we are only beginning to imagine the ways in which changes in their microstructure might project on to their macroscopic structure. Amid ongoing attempts to quantify existing hypotheses, such as those articulated by Albrecht (1989), Pincus and Baker (1994), and Twomey (1974), new pathways through which atmospheric aerosol, clouds, and precipitation may interact continue to emerge. For instance, for light precipitation in predominantly stratiform clouds, evaporation near

DOI: $10.1175 / 2007 J A S 2428.1$ 
the cloud base destabilizes the subcloud layer and strengthens circulations (Feingold et al. 1996), and thus enhances the coupling to the surface, which leads to stronger circulations and potentially deeper clouds. For heavier precipitation the evaporative cooling is manifest throughout the cloud and subcloud layers, while condensation is confined to the cloud layer. This stabilizes the boundary layer, leading initially to more cumuliform-like convection and less cloudiness. While consistent with some of the early hypotheses, these changes are mediated by nontrivial changes in the boundary layer circulations, which have been shown to affect both the subsequent development of the layer as a whole (Stevens et al. 1998) and the microphysical structure of the cloud (Kogan 2006) in ways that make the ultimate evolution of the system difficult to predict.

For trade wind-like circulations, in which the dominant cloud type is cumuliform, recent work documents the emergence of similarly complex interactions. For instance, simulations by Xue and Feingold (2006) suggest that cloudiness may decrease with increasing amounts of aerosol because the smaller drops that form in such an environment evaporate more readily, thereby accelerating the desiccation of the cloud. The analysis of idealized simulations by Stevens (2007) suggests that precipitation may be important in quenching the growth of the cloud layer, which introduces further pathways through which precipitation can modulate boundary layer structure and hence cloud properties. This argument is consistent with results of Ackerman et al. (2004), which show that because the deepening of the stratocumulus cloud layer is modulated by precipitation, the response of the layer to the suppression of precipitation can be characterized by either more or less cloud water, depending on the thermodynamic properties of the air mass capping the cloud layer.

The possible interplay between precipitation, boundary layer dynamics, and cloud organization has also emerged as a theme in analyses of data from recent field studies. Illustrative in this respect is the finding that precipitation is often associated with more mesoscale variability, or textured patterns of cloudiness. This is evident in what Stevens et al. (2005) call pockets of open cells (POCs; see also vanZanten and Stevens 2005; Petters et al. 2006), in more linear cloud clearings that Sharon et al. (2006) call rifts, as well as in simple patterns of open cells, such as those analyzed by Comstock et al. (2005). In each case the patterns associated with precipitation tend to be less cloudy than nearby cloud fields in which precipitation is not evident, consistent with the idea that precipitation may play a role in regulating boundary layer circulations and hence patterns of cloudiness and cloud amount.
In this paper we continue a line of investigation that uses large-eddy simulation to help us understand some of the ways in which precipitation effects the organization and structure of trade wind cumuli. We focus on a case of cumulus beneath stratocumulus, loosely based on data collected during the Atlantic Trade Wind Experiment (ATEX), and thus combine some aspects from both shallow convective archetypes. Our simulations produce a domain-averaged surface precipitation rate of $0.65 \mathrm{~mm}$ day $^{-1}$ when the aerosol mixing ratio $N_{a}=25 \mathrm{mg}^{-1}$. [Mixing ratio units of number per milligram $\left(\mathrm{mg}^{-1}\right)$ are preferred to and are approximately the same as $\mathrm{cm}^{-3}$. The case is interesting because by varying the aerosol loading, different regimes are encountered: for increases in the aerosol loading in clean conditions, cloudiness can increase, only to decrease for more significant increases in the aerosol loading, thus illustrating some of the complexities of aerosol-clouddynamics interactions. The case is also interesting because it provides some of the first evidence of precipitation from shallow convection generating thermodynamic and dynamic perturbations around which subsequent convection then organizes. We proceed as follows: in section 2 a description of the large eddy simulation (LES) model and the trade wind cumulus case is presented. Section 3 presents our results and discussion. Conclusions are given in section 4 .

\section{Model and case description}

Details of the LES model used in this study are given in Xue and Feingold (2006). The model combines a 3D dynamical framework (Stevens et al. 1999) with a sizeresolving microphysical scheme, where cloud droplet spectra are represented by the first two moments of the mass distribution in 33 size intervals covering a radius range of approximately 1.5-2500 $\mu \mathrm{m}$ (Feingold et al. 1996; Stevens et al. 1996). The aerosol size distribution is assumed to be lognormal (median radius $r_{g}=0.1 \mu \mathrm{m}$, and geometric standard deviation $\sigma_{g}=1.5$ ), composed of ammonium sulfate, and fixed in time and space. Aerosol particles with sizes larger than the dry critical size are activated based on equilibrium theory at the local temperature and supersaturation. Warm cloud microphysical processes are simulated.

Two classes of simulations are considered. First, a suite of simulations with aerosol concentrations of $N_{a}=$ $25,50,100,500$, and $2000 \mathrm{mg}^{-1}$ are performed in a doubly periodic $6.4 \mathrm{~km} \times 6.4 \mathrm{~km}$ domain. The upper limit $N_{a}=2000 \mathrm{mg}^{-1}$ is rather extreme, but is nevertheless worth considering because it is an indicator of anticipated microphysical-dynamical interactions asso- 

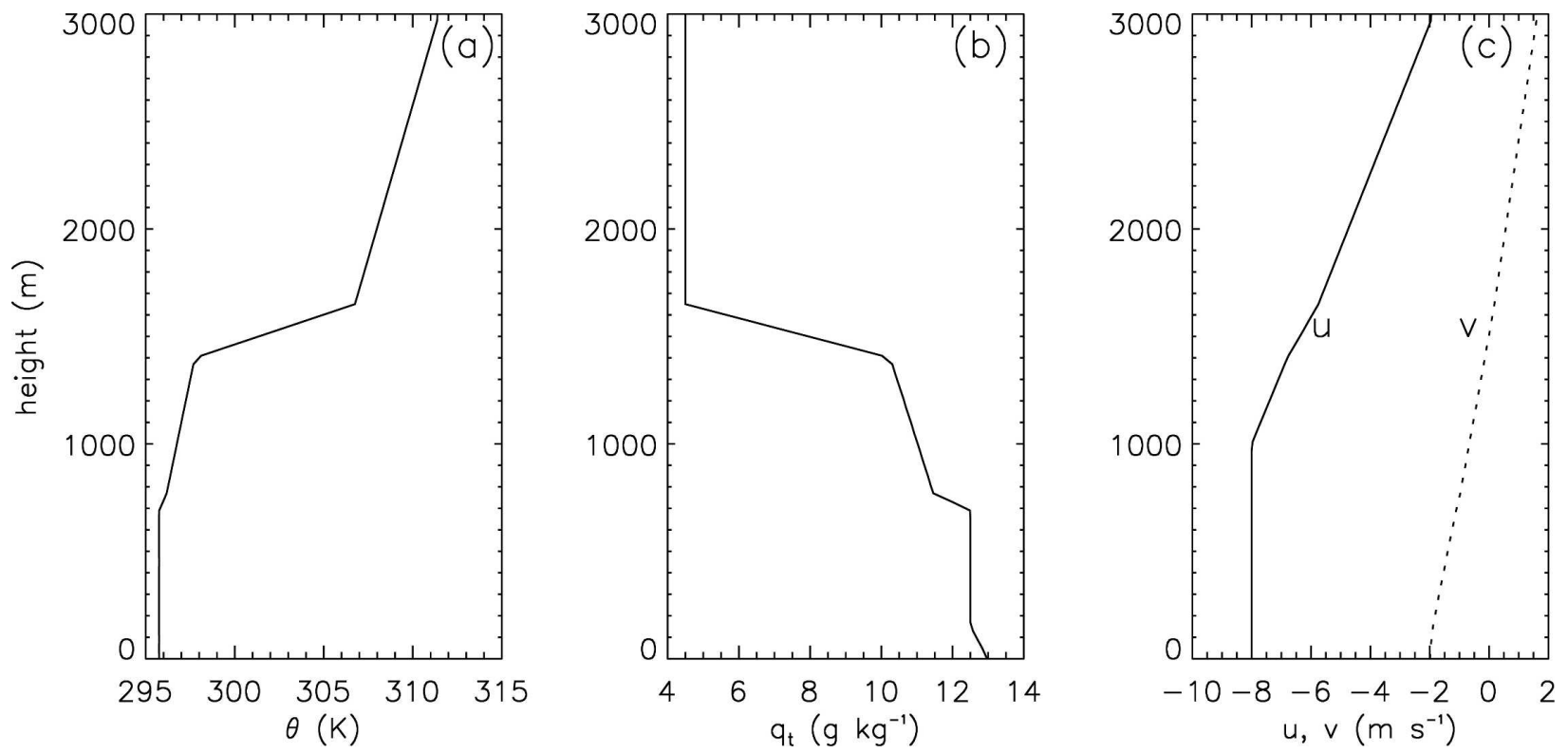

FIG. 1. Initial profiles of the ATEX case used in this study and Stevens et al. (2001): (a) potential temperature, (b) water vapor mixing ratio, and (c) $u$ and $v$ wind components. It is seen that the boundary layer is capped by a strong inversion.

ciated with the equilibrium condensation/evaporation representation in saturation adjustment schemes (e.g., Xue and Feingold 2006). Next, two additional simulations on an approximately fourfold-larger domain (12.4 $\mathrm{km} \times 12.4 \mathrm{~km}$ ), with aerosol concentrations of 25 (highest surface precipitation rate) and $100 \mathrm{mg}^{-1}$ (near-zero surface precipitation rate), are explored. These simulations allow us to address any domain-size sensitivities in our results, as well as to pursue the question of the influence of precipitation on subsequent cloud evolution and structure. For all the simulations, the depth of the domain is $3 \mathrm{~km}$; the model grid spacing is $\Delta x=$ $\Delta y=100 \mathrm{~m}$ and $\Delta z=20 \mathrm{~m}$; the time step is $1.0 \mathrm{~s}$. The domain size and resolutions are the same as those in the ATEX intercomparison case of the Global Water and Energy Experiment (GEWEX) Cloud System Studies (GCSS) Boundary Layer Working Group. Each of the simulations is run for $6 \mathrm{~h}$ of simulated time, but only the last $4 \mathrm{~h}$ are used in the analysis.

The simulations are initialized homogeneously in the horizontal (but with small-amplitude, random perturbations to break the initial symmetry) following the prescription in the ATEX intercomparison. These initial conditions are based on an idealization of soundings taken from ATEX. Details of the case can be found in Stevens et al. (2001). The initial thermodynamic profiles are plotted in Fig. 1.

As in the ATEX intercomparison study (Stevens et al. 2001), a simple Beer's law radiation scheme is used to represent the net export of radiant energy,

$$
F(x, y, z, t)=F_{0} \exp \left(-\kappa \int_{z}^{\infty} \rho q_{l} d z\right)
$$

where $\rho$ is the basic-state air density, $q_{l}$ is the liquid water mixing ratio, $F_{0}=74 \mathrm{~W} \mathrm{~m}^{-2}$, and $\kappa=130 \mathrm{~m}^{2}$ $\mathrm{kg}^{-1}$.

Because this is not a case study, we exercise some flexibility in our choice of boundary conditions. Unlike the ATEX intercomparison study, no large-scale advective tendencies of heat or moisture are applied to the model in this study. Moreover, surface fluxes of momentum, heat, and moisture are all prescribed. The fixed surface sensible heat and latent heat fluxes are

$$
\begin{aligned}
& \left(\overline{w^{\prime} \theta^{\prime}}\right)_{s}=1.3 \times 10^{-2} \mathrm{~K} \mathrm{~m} \mathrm{~s}^{-1}, \\
& \left(\overline{w^{\prime} q_{t}^{\prime}}\right)_{s}=8.6 \times 10^{-5} \mathrm{~m} \mathrm{~s}^{-1},
\end{aligned}
$$

which are equivalent to 15 and $250 \mathrm{~W} \mathrm{~m}^{-2}$, respectively. Recent work examining the effects of precipitation on the evolution of the stratocumulus-topped boundary layer, with surface rain rates similar to, or larger than, those reported here explored whether or not a more realistic prescription of the surface fluxes (e.g., by fixing the surface temperature) significantly affects the flow evolution (Savic-Jovcic and Stevens 2008). In that study it was found that horizontal variations of the surface fluxes (e.g., as related to the development of the cold pools) had no significant effect on the resulting circulations, hence motivating our use of a constant flux 
TABLE 1. Averaged cloud properties in the larger domain simulations as compared to the smaller domain runs for $N_{a}=25$ and $100 \mathrm{mg}^{-1}$. Values in parentheses represent std dev.

\begin{tabular}{lccccc}
\hline \hline & \multicolumn{2}{c}{$N_{a}=25 \mathrm{mg}^{-1}$} & & \multicolumn{2}{c}{$N_{a}=100 \mathrm{mg}^{-1}$} \\
\cline { 2 - 3 } & Smaller domain & Larger domain & & Smaller domain & Larger domain \\
\hline Cloud fraction & $0.580(0.0422)$ & $0.582(0.0235)$ & & $0.657(0.0724)$ & $0.615(0.0727)$ \\
LWP $\left(\mathrm{g} \mathrm{m}^{-2}\right)$ (domain average) & $70.7(15.8)$ & $72.6(16.9)$ & & $46.5(8.35)$ & $45.1(9.89)$ \\
LWP $\left(\mathrm{g} \mathrm{m}^{-2}\right)$ (cloud average) & $122(30.8)$ & $123(27.6)$ & & $69.4(8.59)$ & $71.1(8.53)$ \\
TKE $\left(\mathrm{kg} \mathrm{s}^{-2}\right)$ & $992(176)$ & $1133(288)$ & & $774(80.4)$ & $774(102)$ \\
Maximum $w\left(\mathrm{~m} \mathrm{~s}^{-1}\right)$ & $4.8(0.80)$ & $5.5(0.56)$ & & $5.6(0.78)$ & $6.3(0.60)$ \\
Surface rain rate $\left(\mathrm{mm} \mathrm{day}^{-1}\right)$ & $0.65(0.80)$ & $0.95(0.99)$ & & $1.2 \times 10^{-5}\left(5.8 \times 10^{-5}\right)$ & $1.7 \times 10^{-4}\left(4.4 \times 10^{-4}\right)$ \\
\hline
\end{tabular}

boundary condition here. The surface momentum flux is

$$
\left(\overline{\mathbf{v}^{\prime} w^{\prime}}\right)_{s}=-u_{*}^{2} \frac{\mathbf{v}}{|\mathbf{v}|}
$$

where $u_{*}=0.25 \mathrm{~m} \mathrm{~s}^{-1}$. The horizontal velocities $u$ and $v$ are based on values at the lowest grid level above the surface.

This setup is simple but provides a useful framework for investigating the effects of aerosol on clouds and precipitation. We make no claims on the generality of these results; for example, the aerosol concentration at which drizzle becomes significant enough to modify clouds ( $N_{a}=25 \mathrm{mg}^{-1}$ in this case) should not be viewed as an absolute threshold; the $N_{a}$ at which drizzle becomes significant is expected to vary from case to case.

\section{Results and discussion}

\section{a. Averaged cloud properties at different aerosol number mixing ratios}

A series of simulations performed on the $6.4 \mathrm{~km} \times$ $6.4 \mathrm{~km}$ domain are first considered because they reveal the underlying microphysical processes as well as interesting features pertaining to the effect of aerosol on the average cloud properties, such as cloud fraction, cloud liquid water path (LWP), and vertically integrated turbulence kinetic energy (TKE). These parameters are more sensitive to the aerosol loading than they are to the domain size (Table 1), so that examining how they change in response to a change in the aerosol is worthwhile.

Figure 2 shows the averaged cloud properties for the last $4 \mathrm{~h}$ of simulations at each aerosol mixing ratio $N_{a}$. In each case, vertical lines represent \pm 1 standard deviation from the mean of the last $4 \mathrm{~h}$ of the time series for that simulation. Cloud fraction is defined as the fraction of columns that have LWP $>10 \mathrm{~g} \mathrm{~m}^{-2}$, and cloud-top height is defined as the highest grid point that has $q_{l}>0.01 \mathrm{~g} \mathrm{~kg}^{-1}$. Cloud base is calculated based on the lifting condensation level (LCL), and is thus associated with the base of the cumulus. In addition to the LWP threshold for cloud fraction, we also performed a calculation of cloud fraction based on a visible cloud optical depth threshold of 1 because of the importance of the albedo effect of clouds on climate.

Cloud fraction (defined using both the LWP and optical depth thresholds) initially increases as $N_{a}$ increases from 25 to $100 \mathrm{mg}^{-1}$ (Fig. 2a), but begins to decrease for $N_{a}>100 \mathrm{mg}^{-1}$. The tendency of cloud fraction to decrease for further increases in $N_{a}$ is consistent with the hypothesis of Wang et al. (2003) and Xue and Feingold (2006), wherein for very light precipitation the dominant effect of increasing aerosol concentrations is to reduce the size of detrained drops, which decreases the evaporation time scale, thereby expediting the demise of decaying cloud remnants. This runs counter to the expectation of increased cloud fraction as a result of precipitation suppression. Only in the regime where surface precipitation rates are appreciable do we see the expected tendency of cloudiness to increase with increasing aerosol concentrations. However, even in this regime the domain-averaged LWP decreases monotonically with $N_{a}$ (Fig. 2b). Indeed, the expected tendency of cloud water to increase with decreasing precipitation is only seen in the heavily precipitating regime for that fraction of liquid water contained in cloud droplets with radii $<25 \mu \mathrm{m}$ [dashed line and diamonds in Fig. 2b; see also Jiang and Feingold (2006)]. This indicates not only that a significant amount of liquid water resides in the precipitation mode, but that this liquid water is not removed efficiently from the domain. In other words, the tendency for water to linger due to longer evaporation time scales outweighs the tendency of gravity to expedite its return to the surface. Neither of these effects is considered in current simple constructs of the effects of aerosols on clouds.

Changes in cloud-top heights among the simulations are modest (Fig. 2c). If one focuses only on the nonprecipitating simulations (including those denoted by an asterisk wherein precipitation is artificially sup- 

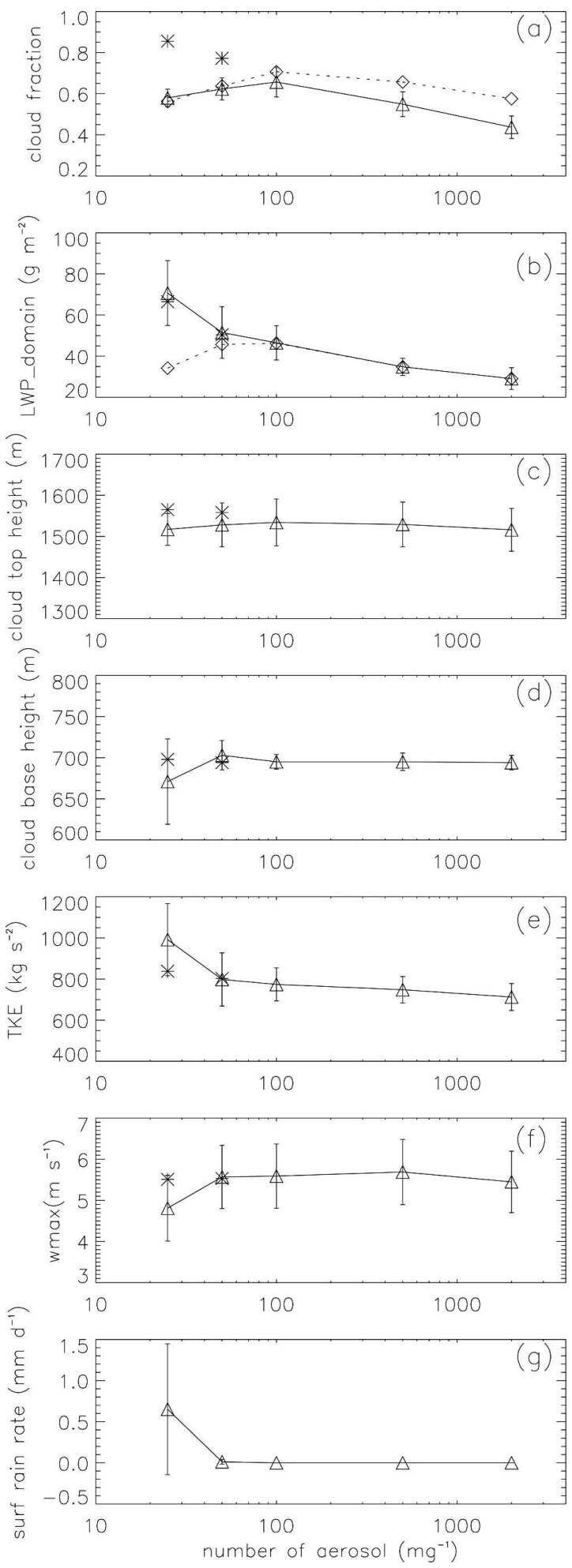

FIG. 2. Averaged cloud properties as a function of different aerosol concentrations: (a) cloud fraction, (b) domain-averaged LWP, (c) cloud-top height, (d) cloud-base height, (e) vertically integrated TKE, (f) maximum $w$, and (g) surface precipitation rate. Dashed line and diamonds in (a) are the results based on a visible optical depth threshold of 1 . Dashed line and diamonds in pressed even in the presence of large drops), there is a tendency for cloud-top height to increase with decreasing aerosol concentration. However, with the onset of precipitation this tendency reverses and cloud-top heights fall with decreasing aerosol and increasing precipitation; similarly, the strengths of the updrafts, as measured by the maximum updraft velocity, weaken (Fig. 2f). These latter effects are consistent with Stevens (2007) who argued that an increase in the precipitation reduces the flux of liquid water into the inversion, which provides the energetic support for the growth of the cumulus layer. Cloud-base height decreases with increasing precipitation (Fig. 2d), showing that precipitation affects the thermodynamical state of the subcloud layer, which (following Neggers et al. 2006) could have implications for the mass flux out of this layer. The tendency of the turbulence kinetic energy to increase with increasing precipitation reflects an increase in horizontal variability, consistent with the effects of evaporating precipitation on the subcloud layer (Fig. 2e).

The precipitation rate decreases as aerosol concentration increases (Fig. 2g). The domain-averaged surface precipitation rate changes from 0.65 to $0.012 \mathrm{~mm}$ day $^{-1}$ to nearly 0 as aerosol concentration increases from 25 to 50 to $100 \mathrm{mg}^{-1}$. Overall, the differences between the results for $N_{a}=25 \mathrm{mg}^{-1}$ with and without precipitation suggest that precipitation may be an important factor in determining cloud and boundary layer evolution.

Figure 3 shows temporally and spatially averaged profiles of cloud fraction, domain- and cloud-averaged values of $q_{l}$, as well as the net condensation rate, effective radius, and precipitation rate for three different values of $N_{a}$. Here, cloud fraction at each height is defined as the fraction of grid points that have $q_{l}>0.01 \mathrm{~g}$ $\mathrm{kg}^{-1}$ at that height; cloud-averaged values are those averaged over the cloudy columns that have LWP $>10$ $\mathrm{g} \mathrm{m}^{-2}$. Figure 4 shows histograms of the vertical velocity $w$ at a variety of levels. In both figures results are only shown for three simulations $-N_{a}=25,100$, and $2000 \mathrm{mg}^{-1}$-because these span the range of behavior simulated. The profiles document the hybrid structure of the clouds observed during ATEX, wherein a distinct cumulus mode underlies and feeds an overlying

$\leftarrow$

(b) are the results based on calculations that only consider cloud droplets with radii $<25 \mu \mathrm{m}$. Asterisks are the results from the simulations without collision-coalescence and sedimentation to isolate precipitation effects. Vertical lines represent \pm 1 std dev from the mean of the last $4 \mathrm{~h}$ of the time series for that simulation. 

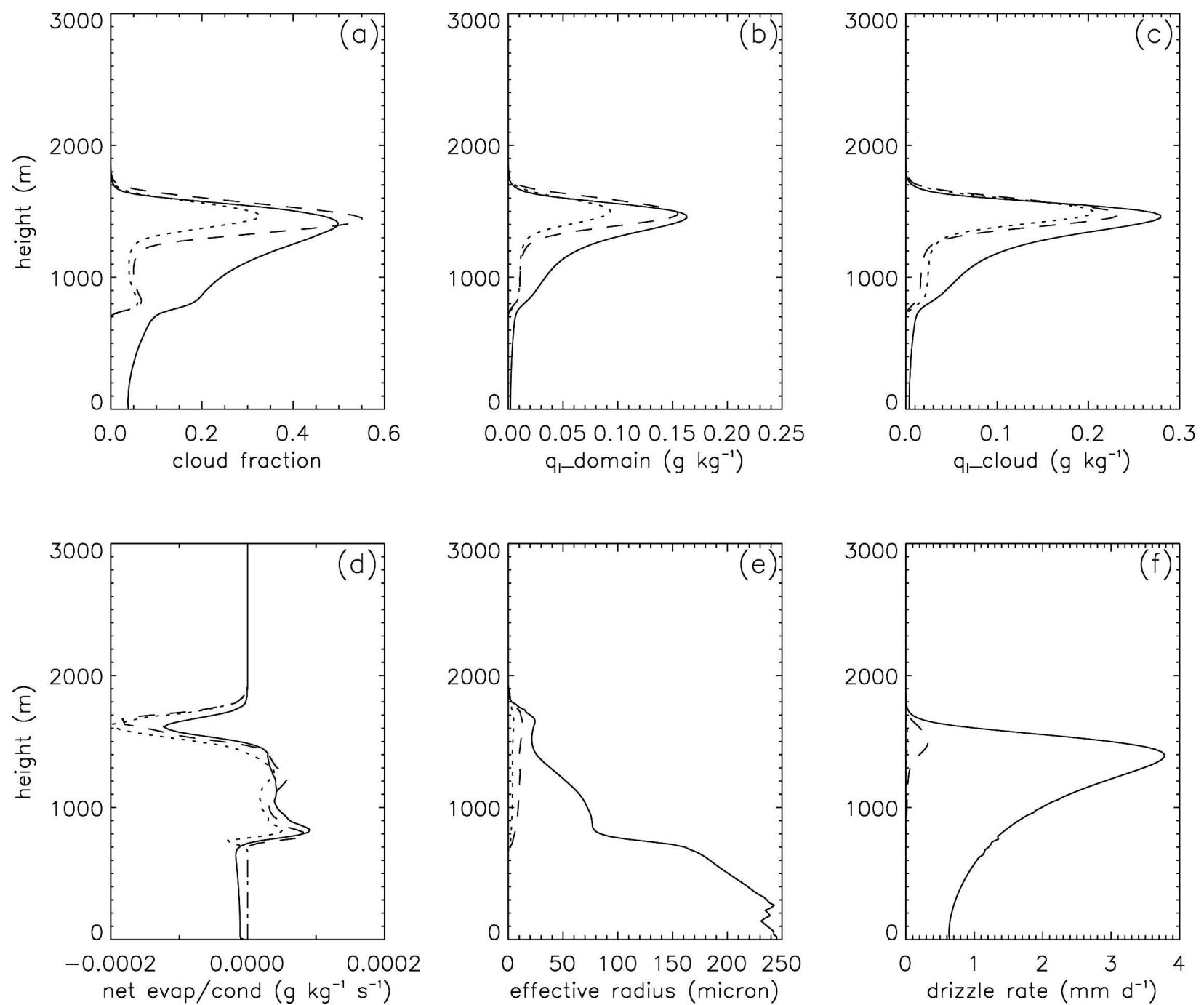

FIG. 3. Profiles of (a) cloud fraction, (b) domain-averaged $q_{l}$, (c) cloud-averaged $q_{l}$, (d) domain-averaged net evaporation and condensation rates, (e) effective radius, and (f) precipitation (drizzle) rate. Solid to more broken line styles represent increasing levels of aerosol with $N_{a}=25 \mathrm{mg}^{-1}$ (solid), $N_{a}=100 \mathrm{mg}^{-1}$ (dashed), and $N_{a}=2000 \mathrm{mg}^{-1}$ (dotted).

stratiform layer. The histograms show that in the cumulus layer $(1000 \mathrm{~m}) w$ is positively skewed, with strong relatively rare updrafts balanced by weak but widespread downdrafts. In the stratiform layer $(1400 \mathrm{~m})$, stronger downdrafts contribute markedly to the circulation. Although the two layers of cloudiness are coupled, with cumulus drafts rising up and feeding moisture into the upper stratiform layer, the balance of cloudiness in each regime can be expected to depend on different processes, and thus may respond differently to perturbations in environmental conditions.

In the nonprecipitating regime both cloud fraction and domain-averaged liquid water decrease as $N_{a}$ increases from 100 (dashed line) to $2000 \mathrm{mg}^{-1}$ (dotted line) (Figs. 3a,b). This decrease occurs entirely in the upper stratiform layer and is consistent with the shorter evaporative time scales of smaller drops as described by Xue and Feingold (2006). The relatively small difference in both cloud-averaged $q_{l}$ and net condensation in the stratiform layer between these two nonprecipitating simulations (Figs. 3c,d), as well as the similarity in the histograms of $w$, suggests that the underlying topology of the flow is similar. Most of the difference in the domain-averaged stratiform cloud water amount is a simple expression of the decrease in cloud fraction with increasing aerosol. While one might have expected a deepening of the layer due to enhanced evaporation (Stevens 2007), the fact that the cloud layer does not deepen as $N_{a}$ increases, may be due to the fact that at higher $N_{a}$ the lower cloud fraction reduces the radiative 

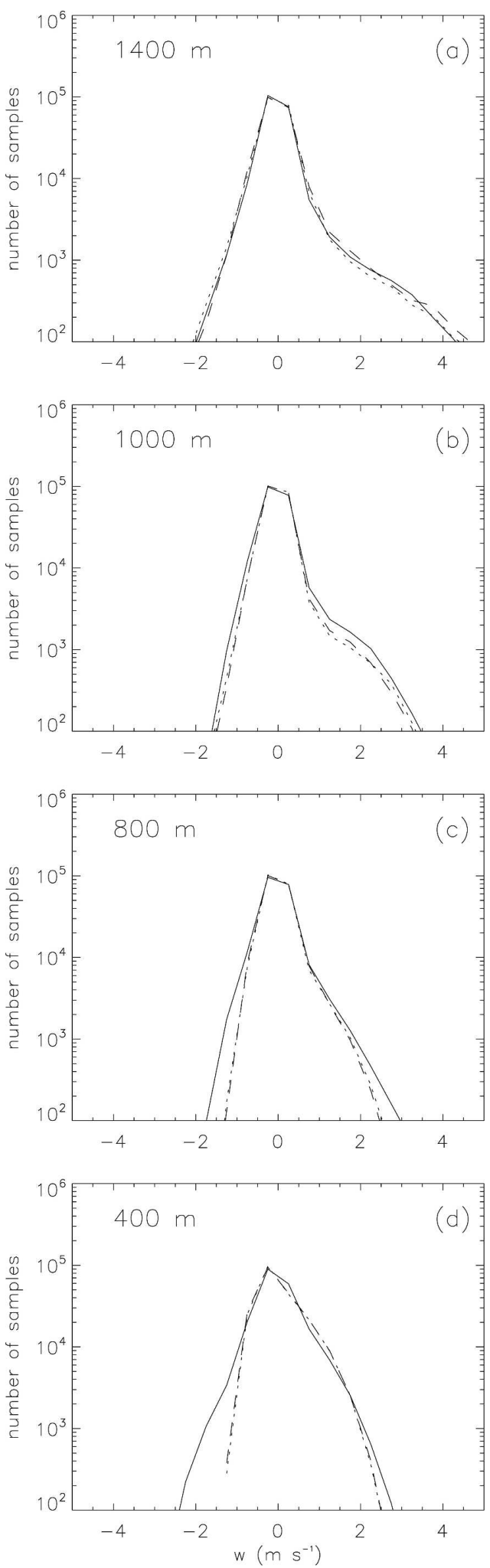

FIG. 4. Histograms of $w$ at different levels (m) for three different aerosol concentrations: (a) 1400, (b) 1000, (c) 800, and (d) 400. Solid to more broken line styles represent smaller to larger aerosol concentrations, as in Fig. 3. driving of the circulations within the stratiform layer. [Recall that the radiative cooling is a function of cloud water; see Eq. (1).] Note that, between these two nonprecipitating simulations, differences in the structure of the cumulus layer are smaller than those in the upper stratiform layer.

In contrast, a different set of processes becomes evident in what we will call the precipitation regime, illustrated through a comparison of both the cloud profiles (Fig. 3) and histograms of $w$ (Fig. 4), between the simulations with $N_{a}$ equal to 100 (dashed line) and $25 \mathrm{mg}^{-1}$ (solid line). In these simulations the differences in the overlying stratiform layer are smaller than those in the cumulus layer. As the cloud drops grow large enough (Fig. 3e) for precipitation to contribute significantly to the liquid water budget (Fig. 3f), we expect the cloud layer to deepen less rapidly (as argued by Stevens 2007). In this limit the transport of liquid water into the inversion layer is increasingly balanced by precipitation (consistent with the reduced evaporation rates in Fig. 3). Precipitation will tend to offset the previously described tendency of larger drops to linger at a level and increase the stratiform cloudiness. Indeed, the stratiform cloud fraction changes little between the two simulations. While large drops may linger, their lifespan depends on both how readily they evaporate and on how rapidly they fall to the surface; thus their longevity no-longer concentrates at a particular level, but is instead spread by precipitation through the entirety of the cloud and subcloud layers. Such effects are long familiar to the casual observer of lingering rain shafts or virga that remain long after the disappearance of the original cloud, and suggest that depending on when in the life cycle of the cloud rain forms, it may actually increase, rather than decrease, the lifespan of the condensate.

The effects of precipitation on the turbulent flow structure are also illustrated with the help of Fig. 5, which presents profiles of vertical velocity variance and buoyancy fluxes, conditionally averaged over positive and negative $w$. These show the clear influence of precipitation for $N_{a}=25 \mathrm{mg}^{-1}$, on the circulation. The clean case is characterized by higher subcloud $w$ variance and buoyancy flux in the downdrafts as a result of evaporating precipitation (Figs. 5a,b; see also Fig. 4d). Updrafts are characterized by weaker $w$ variance in the lowest $600 \mathrm{~m}$, but stronger $w$ variance in the vicinity of the cloud base and in the cumulus layer (Figs. 5c,d; see also Figs. 4b-d). Closer examination of Fig. 4d reveals that individual updrafts tend to be more frequent in the magnitude range of $0-0.3 \mathrm{~m} \mathrm{~s}^{-1}$ for the clean case. However, it is the less frequent updrafts in the range of 

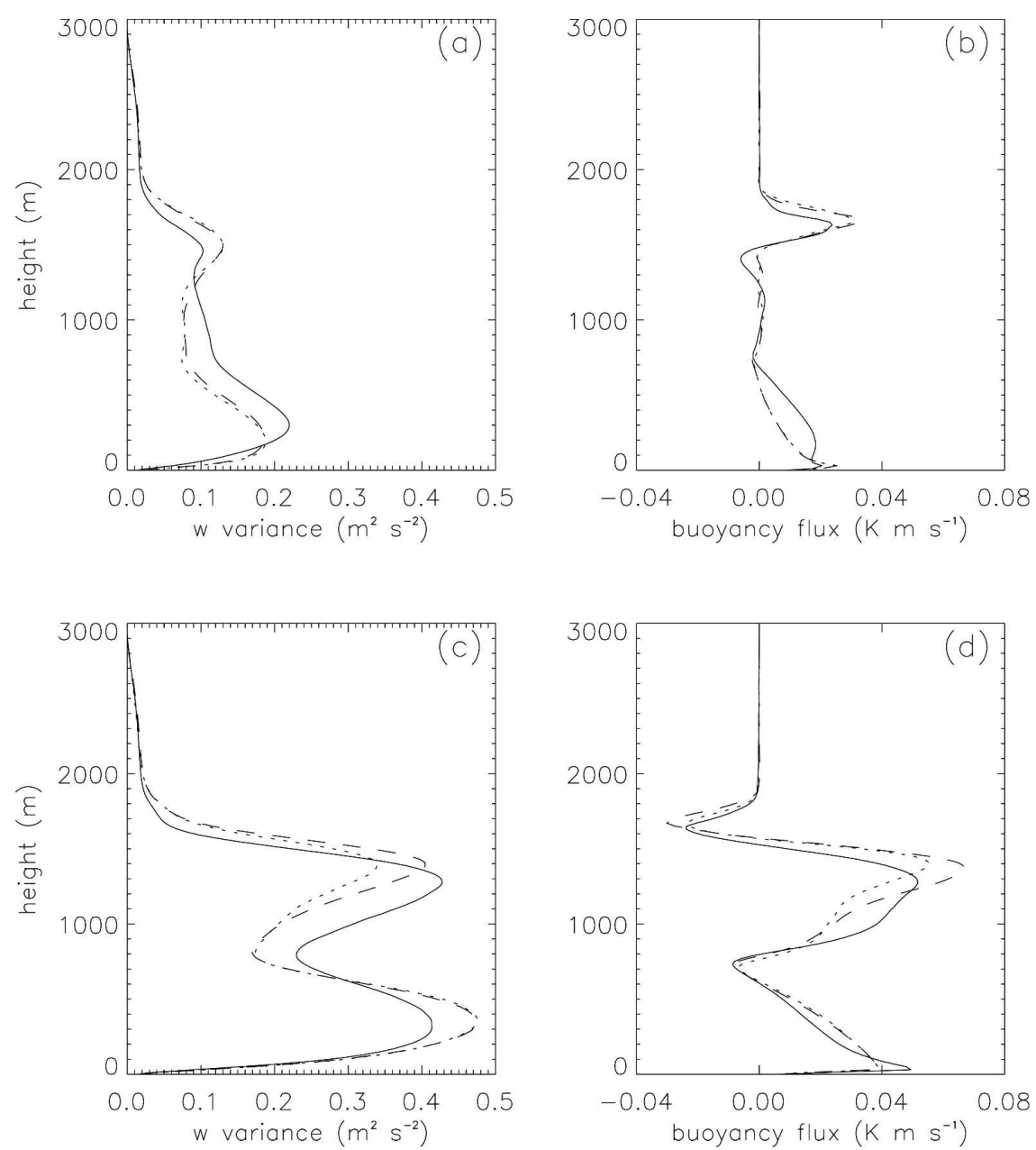

FIG. 5. Domain-averaged profiles of turbulence ( $w$ variance) and buoyancy flux: $w$ variance (a) downdrafts and (c) updrafts; buoyancy flux (b) downdrafts and (d) updrafts. Solid to more broken line styles represent $N_{a}=25,100$, and $2000 \mathrm{mg}^{-1}$, respectively.

$0.3-0.8 \mathrm{~m} \mathrm{~s}^{-1}$ that contribute most to the weaker subcloud $w$ variance.

\section{b. Effects of precipitation on the organization of trade wind cumuli}

As motivation to this section, we present satellite imagery that provides some intriguing images of the evolution of trade cumulus cloud fields. During the Rain in Cumulus over the Ocean (RICO; see Rauber et al. 2007) experiment, Geostationary Operational Environmental Satellite (GOES) visible images were archived at regular intervals. A series of these channel 1 (visible) images were taken by the GOES-12 satellite on 16 January 2005 and are shown in Fig. 6. The images cover the $18^{\circ}-20^{\circ} \mathrm{N}$ and $60^{\circ}-64^{\circ} \mathrm{W}$ domain at a spatial resolution of $1 \mathrm{~km} \times 1 \mathrm{~km}$ from 1545 to 1845 UTC. We draw the reader's attention to the arrow in Fig. $6 \mathrm{f}$ indicating the primary region of interest. The first images
(1545 UTC) show no particular organization between $60^{\circ}$ and $62^{\circ} \mathrm{W}$ (the right half of the domain), but some evidence of hexagonal, cellular structure between $62^{\circ}$ and $64^{\circ} \mathrm{W}$. With increasing time, cellular structure begins to develop between $60^{\circ}$ and $62^{\circ} \mathrm{W}$ (e.g., 1715 UTC) until open cells are formed. These cells have low reflectance cloud(s) somewhere within, and show distinct signs of convection around their perimeters (e.g., 1815 UTC). By 1845 UTC there is no longer any evidence of cloud in the center of the cell (region indicated by arrow).

To address the question of whether such features are consistent with effects that might ensue with the development of precipitation, we present results from simulations in the precipitating $\left(N_{a}=25 \mathrm{mg}^{-1}\right)$ and nonprecipitating $\left(N_{a}=100 \mathrm{mg}^{-1}\right)$ regimes for a fourfold larger horizontal domain $(12.4 \mathrm{~km} \times 12.4 \mathrm{~km})$. Note that cell sizes observed in the GOES imagery are on the order of $40 \mathrm{~km}$, that is, significantly larger than the 

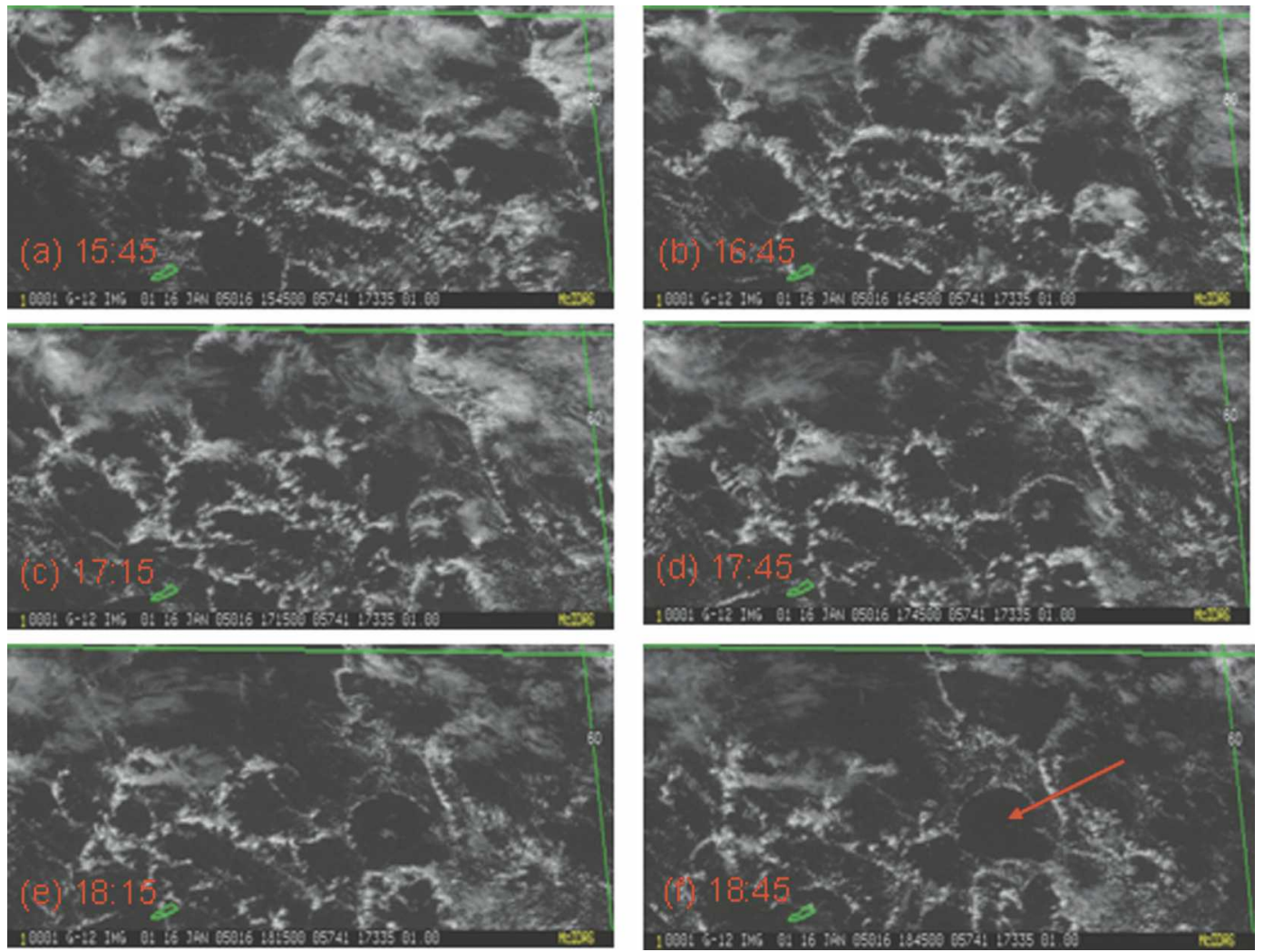

FIG. 6. GOES visible imagery of the development of precipitating open cells from the area studied during RICO. Images are shown at (a) 1545, (b) 1645, (c) 1715, (d) 1745, (e) 1815, and (f) 1845 UTC. The images are bounded on the right by $60^{\circ} \mathrm{W}$ and on the left by $64^{\circ} \mathrm{W}$. The latitudinal range is $18^{\circ}-20^{\circ} \mathrm{N}$. The arrow in (f) points to the primary region of interest.

model domain. Although larger model domain simulations would be preferable, the key processes appear to be sufficiently well represented in this domain, at least at early times when the largest scales are still significantly smaller than the size of the domain. Simulations using the smaller $6.4 \mathrm{~km} \times 6.4 \mathrm{~km}$ domain exhibit similar features (Table 1), although domain size restrictions become evident somewhat earlier, and as such they provide a less satisfying framework for addressing the mesoscale organization of trade wind cumuli (Stevens et al. 2002).

Figure 7 presents snapshots of the flow structure between $t=2.5 \mathrm{~h}$ and $t=4 \mathrm{~h}$ for the simulation with $N_{a}=25 \mathrm{mg}^{-1}$. The near surface $(z=60 \mathrm{~m})$ horizontal cross sections of precipitation and the convergence are given in the left column. The center column presents the corresponding LWP fields superimposed on the near-surface convergence, while the right column shows the time rate of change of LWP (elaborated upon below) superimposed on the near-surface convergence. As we shall see, the surface convergence field proves to be a good indicator of the organization of the circulation. The time series of surface precipitation (Fig. 8) shows that precipitation gradually develops after $2.5 \mathrm{~h}$ into the simulation, and becomes strongest between $t=4 \mathrm{~h}$ and $t=5 \mathrm{~h}$. The mean of the last $4 \mathrm{~h}$ of the surface precipitation rate is $0.95 \mathrm{~mm} \mathrm{day}^{-1}$ (Table 1).

Between $t=2.5 \mathrm{~h}$ and $t=4 \mathrm{~h}$ the flow visualization exhibits a distinct transition to an open cellular structure as a result of precipitation from initially unorganized convection. At 2 h 30 min (Fig. 7a), precipitation is barely evident and the flow is organized in an irregular network of cells of about $1-2 \mathrm{~km}$ in size and elongated in the direction of the mean wind ( $\sim$ northeast). At $3 \mathrm{~h} 15 \mathrm{~min}$, precipitation at the surface becomes marked, and precipitating regions become ringed by a narrow band of convergence that is somewhat intensified on the downwind side (Fig. 7d). This ring of convergence spreads with time (Figs. 7g,j) in a manner that suggests it represents the boundary of a spreading cold pool that forms as a result of the evaporation of precipitation from the initial convection. This interpretation is consistent with the thermodynamic structure of 

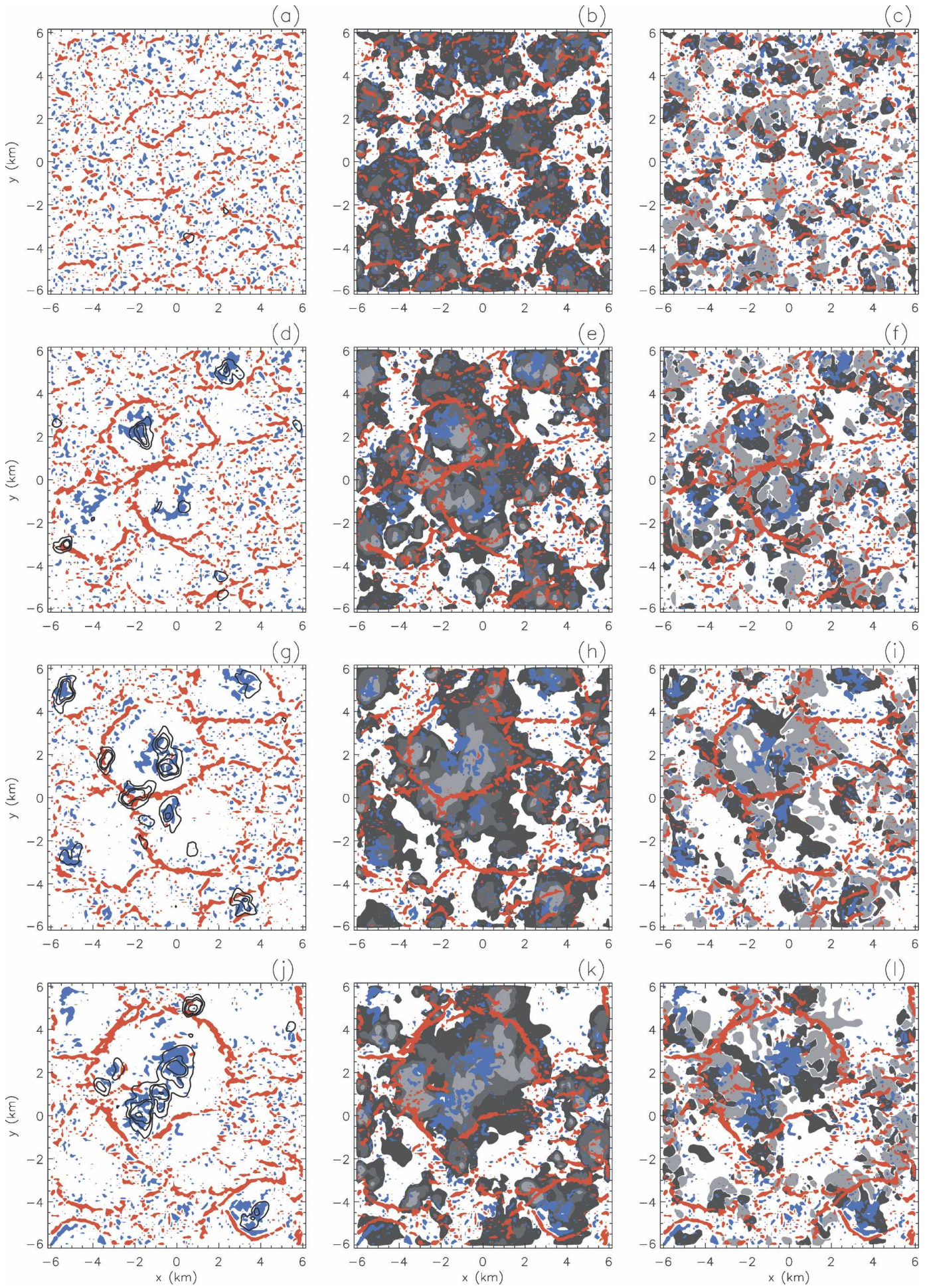

FIG. 7. Snapshots of the flow structure for $N_{a}=25 \mathrm{mg}^{-1}$ and $12.4 \mathrm{~km} \times 12.4 \mathrm{~km}$ domain size at (a)-(c) $2 \mathrm{~h} 30$ min, (d)-(f) $3 \mathrm{~h} 15 \mathrm{~min}$, (g)-(i) $3 \mathrm{~h} 30 \mathrm{~min}$, and (j)-(1) $3 \mathrm{~h} 45 \mathrm{~min}$. Superimposed on the near-surface $(z=60 \mathrm{~m})$ color-coded convergence fields are (left) surface precipitation rate (contours), (center) LWP (shading), and (right) time rate of change of LWP $(d \mathrm{LWP} / d t)$ (shading). Red regions represent convergence $\left(<-0.005 \mathrm{~s}^{-1}\right)$; blue regions represent divergence $\left(>0.005 \mathrm{~s}^{-1}\right)$. Precipitation contours have values of 1.0, 5.0,10.0, and $50.0 \mathrm{~mm} \mathrm{day}^{-1}$. LWP shadings represent values of 10,100 , and $300 \mathrm{~g} \mathrm{~m}^{-2}$, and larger. The shading goes from dark to bright as LWP increases. Positive $d \mathrm{LWP} / d t\left(>5 \mathrm{~g} \mathrm{~m}^{-2} \mathrm{~min}^{-1}\right)$ is shown in bright shading, and negative $d \mathrm{LWP} / d t\left(<-5 \mathrm{~g} \mathrm{~m}^{-2}\right.$ $\left.\min ^{-1}\right)$ is shown in dark shading. Note that the white space in the center and right columns does not constitute a contouring level; $d \mathrm{LWP} / d t$ at time $t$ is calculated as $[\mathrm{LWP}(t+\Delta t)-\operatorname{LWP}(t)] / \Delta t$, where $\Delta t=5 \mathrm{~min}$. 


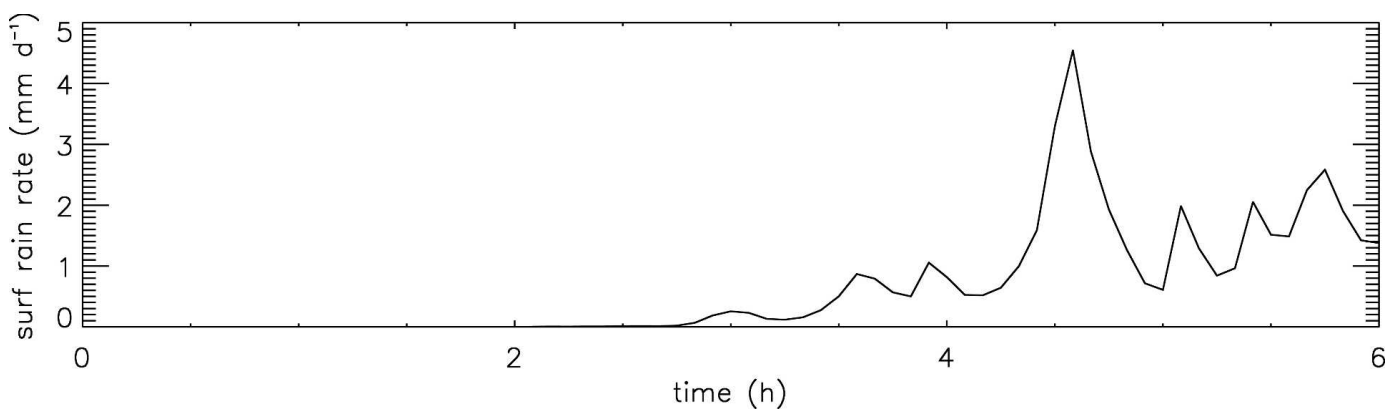

FIG. 8. Time series of the surface precipitation rate for the $N_{a}=25 \mathrm{mg}^{-1}$ and the $12.4 \mathrm{~km} \times 12.4 \mathrm{~km}$ domain simulation shown in Fig. 7.

the flow given in Fig. 9, which shows that the spreading ring of convergence is associated with the edge of warmer and moister air. The convergence on the leading edge of the cold pool is supported by divergent motion within the cold pool.

This pattern of surface convergence and divergence can be expected to focus new convection in regions of convergence. Such features are evident in the cross sections of LWP and its evolution (center column of Fig. 7). As new cells develop and generate their own precipitation, they in turn induce downdrafts and create their own divergent zones at the surface (e.g., the large cell at $3 \mathrm{~h} 45 \mathrm{~min}$; Fig. 7j). It is seen that the loose network of cells is increasingly dominated by such convergence lines, and that they exhibit a structure reminiscent of patterns of open cellular convection (e.g., Stevens et al. 2005). As time progresses the size of the cells increases until the domain is dominated by one cell. New precipitating cells continue to develop at the convergence zones, as can be seen at $3 \mathrm{~h} 45 \mathrm{~min}$ (e.g., Fig. $7 \mathrm{j} ; x=0.5 \mathrm{~km}, y=5 \mathrm{~km}$ ). This succession of cumulus cell development in the convergence zones and the precipitation-induced divergence appears to be elemental to the initiation and maintenance of the cumulus layer.

A closer look at the LWP field reveals that the time rate of decrease in LWP $(d \mathrm{LWP} / d t)$ is often associated with the precipitation-induced divergence zones at the center of the open cellular structure \{right column of Fig. 7, where $d \mathrm{LWP} / d t$ at time $t$ is calculated as $[\operatorname{LWP}(t+$ $\Delta t)-\mathrm{LWP}(t)] / \Delta t, \Delta t=5 \mathrm{~min}\}$. The removal of water via drizzle not only leads to decreased LWP, but also to a negatively buoyant cold pool (Fig. 9b), downdrafts (Fig. 9b), and divergence fields (Fig. 9a,c). It is also seen that positive $d \mathrm{LWP} / d t$ is often associated with convergence zones, driving updrafts, and the formation of new cells along the edges of (although not necessarily aligned with) the open cellular structure. (Figure 71 shows numerous examples of this around the edges of the dominant cell, and along the arc that extends from $x=1 \mathrm{~km}, y=-6 \mathrm{~km}$ to $x=5 \mathrm{~km}, y=2 \mathrm{~km}$.) As the LWP decreases at the center and increases at the edge of the cell, the mesoscale open cellular structure is formed and maintained. Notice that at $3 \mathrm{~h} 45 \mathrm{~min}$, the open cell size is about $6 \mathrm{~km}$ in diameter and the drizzle patch is about $3-4 \mathrm{~km}$, indicating that the cloud structure in this case indeed has mesoscale dimensions and characteristics. With time the cell grows even larger until it fills the domain (figure not shown). At this point the simulations are increasingly influenced by the periodicity in the horizontal boundary conditions.

Figure 10a shows select horizontal cross-sectional views of the surface precipitation and the convergencedivergence fields near the surface $(z=60 \mathrm{~m})$ for $N_{a}=$ $100 \mathrm{mg}^{-1}$ at $3 \mathrm{~h} 30 \mathrm{~min}$. Surface precipitation is nearly zero in this case. The divergence-convergence fields show no organization in this figure, or at other times in the simulation. There is also no evolution from open to closed cellular structure for $N_{a}=100 \mathrm{mg}^{-1}$. The corresponding LWP field is shown in Fig. 10b.

We reiterate the fact that there is a large disparity between the modeled and observed cell sizes (cf. Figs. 6 and 7). Thus, care should be taken before drawing a direct link between the observations and simulations. The scale of these features and their relationship to mesoscale forcing needs to be studied to establish the relevance of these simulations to the observed features. Nevertheless, the nature of the evolution of these features suggests that the precipitation and the divergence-convergence patterns simulated here are not obviously inconsistent with the observed open cell structure.

\section{c. Life cycle of precipitating cells}

Because precipitation plays a significant role in the organization of trade cumulus clouds, it is of interest to examine the life cycle of precipitating cells more closely. Section 3a raised the question of aerosol effects that might increase or reduce the lifetime of water droplets in a cloud. An increase in aerosol concentra- 


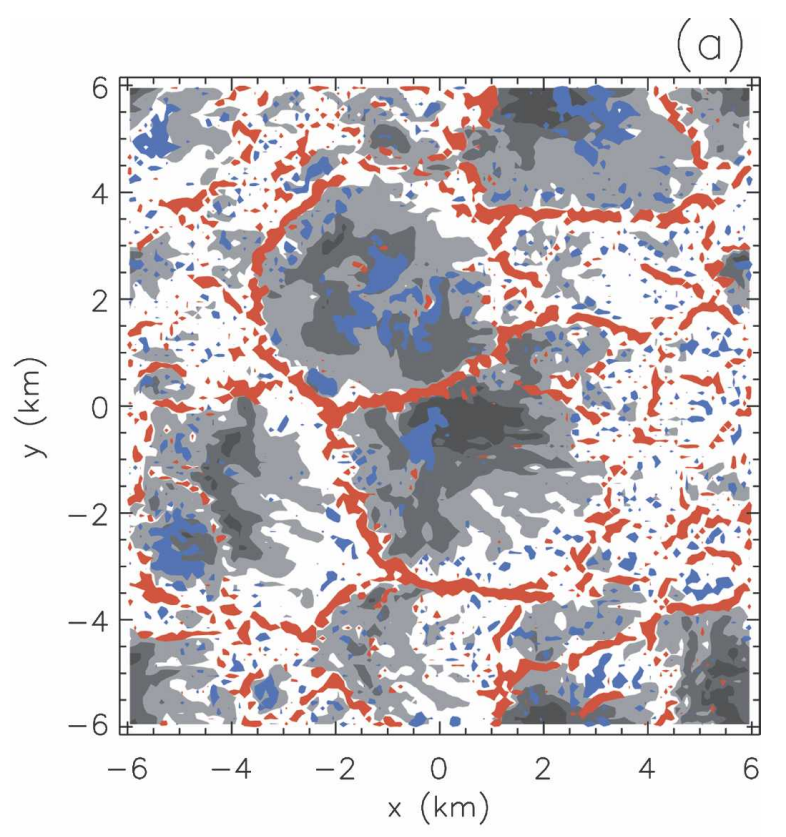

(b)
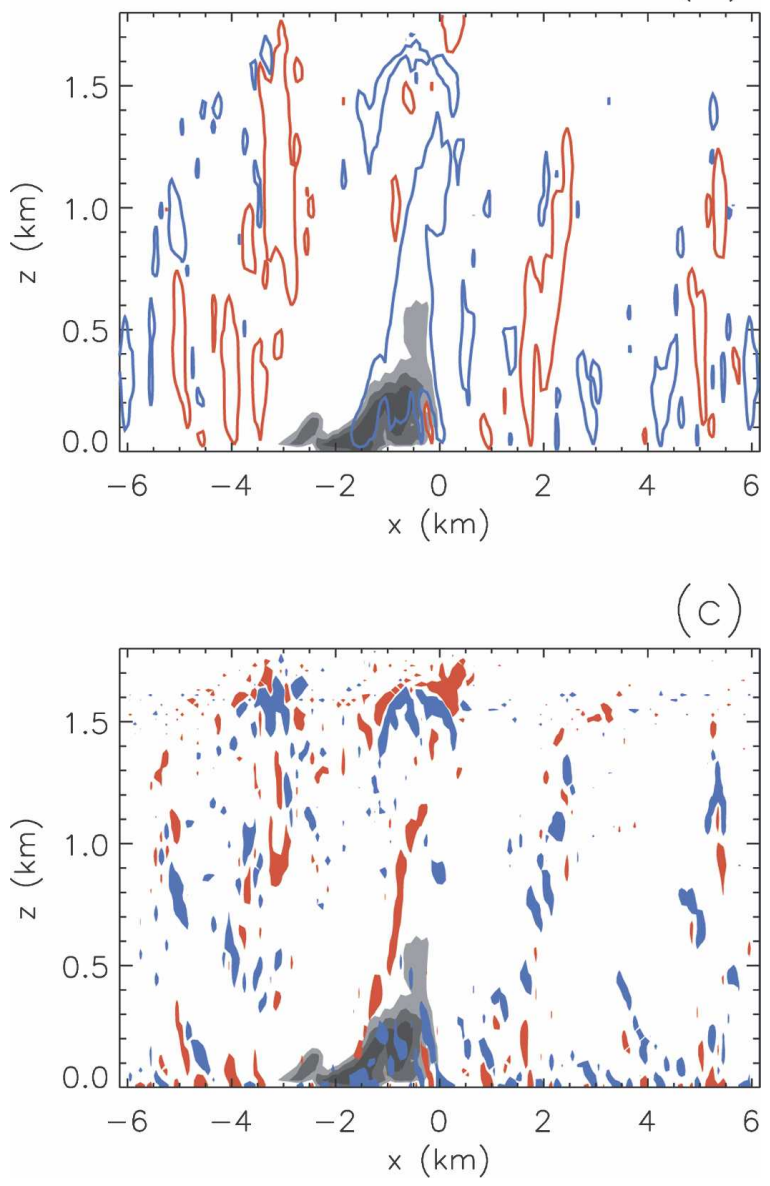

FIG. 9. Snapshots at $3 \mathrm{~h} 30 \mathrm{~min}$ for $N_{a}=25 \mathrm{mg}^{-1}$ and $12.4 \mathrm{~km} \times$ $12.4 \mathrm{~km}$ domain simulation shown in Fig. 7: (a) total water mixing ratio (shading) superimposed on the convergence-divergence tion will tend to reduce the residence time of water by increasing the efficiency of evaporation, whereas there will be a counteracting effect of an increase in residence time due to suppression of precipitation. In Jiang et al. (2006) we showed that for small, weakly precipitating cumulus [Barbados Oceanographic and Meteorological Experiment (BOMEX)] an almost 100-fold increase in aerosol concentration $\left(25-2000 \mathrm{mg}^{-1}\right)$ had no effect on the mean lifetime of hundreds of individual cloud cells. For the more strongly precipitating clouds considered here, we reconsider this question.

Results shown in this section derive from the simulation of the $N_{a}=25 \mathrm{mg}^{-1}$ and $N_{a}=100 \mathrm{mg}^{-1}$ cases over the $12.4 \mathrm{~km} \times 12.4 \mathrm{~km}$ domain. The strong convective cells (defined as having LWP $>100 \mathrm{~g} \mathrm{~m}^{-2}$ ) are tracked over the course of their lifetimes based on model output of LWP at a resolution of $1 \mathrm{~min}$. The methodology for the calculation of cloud lifetime is discussed in more detail in Jiang et al. (2006). The analysis of these simulations shows no distinct differences in the mean lifetime of clouds for the $25 \mathrm{mg}^{-1}$ versus 100 $\mathrm{mg}^{-1}$ cases. Table 2 examines this in further detail by stratifying the mean lifetime for different lifetime categories. For all categories, the difference is less than $5 \%$. We thus conclude that the major influences of the aerosol are manifested as changes in cloud morphology and precipitation, but that as in Jiang et al. (2006) there is negligible influence on the mean lifetime of these stronger cloud cells. This means that changes in cloud fraction that emerge in the presence of precipitation, whether it be changes in the stratiform area or cumulus fractions, must represent some combination of changes in convective frequency or in the size of individual cells. An analysis of the cloud sizes shows that the $100 \mathrm{mg}^{-1}$ clouds are smaller in horizontal dimension than the 25 $\mathrm{mg}^{-1}$ clouds (figure not shown). Similar influences of aerosol on cloud size were noted by Xue and Feingold (2006). However, the $100 \mathrm{mg}^{-1}$ clouds are more numer-

$\leftarrow$

field at $z=60 \mathrm{~m}$, (b) vertical cross section of $\theta_{v}$ (shading) superimposed with vertical velocity contours at $y=2 \mathrm{~km}$, and (c) vertical cross section of $\theta_{v}$ superimposed on the convergencedivergence field at $y=2 \mathrm{~km}$. Red-shaded regions represent convergence $\left(<-0.005 \mathrm{~s}^{-1}\right)$ and blue regions represent divergence $\left(>0.005 \mathrm{~s}^{-1}\right)$; red contours represent updrafts $\left(w>0.5 \mathrm{~m} \mathrm{~s}^{-1}\right)$ and blue contours represent downdrafts $\left(w<-0.5 \mathrm{~m} \mathrm{~s}^{-1}\right)$; grayshaded total water mixing ratio contours have values of $12.0,12.5$, and $13.0 \mathrm{~g} \mathrm{~kg}^{-1}$; gray-shaded $\theta_{v}$ contours have values of 298.1, 298.2, and $298.3 \mathrm{~K}$; in both cases shading becomes brighter as the value of the contoured variable increases. Note the drier and more negatively buoyant regions within the open cells. Also note the downdrafts in the center of the cell and updrafts at the edges in the zones of convergence $(x \sim-3.5 \mathrm{~km}$ and $x \sim 2 \mathrm{~km})$. 

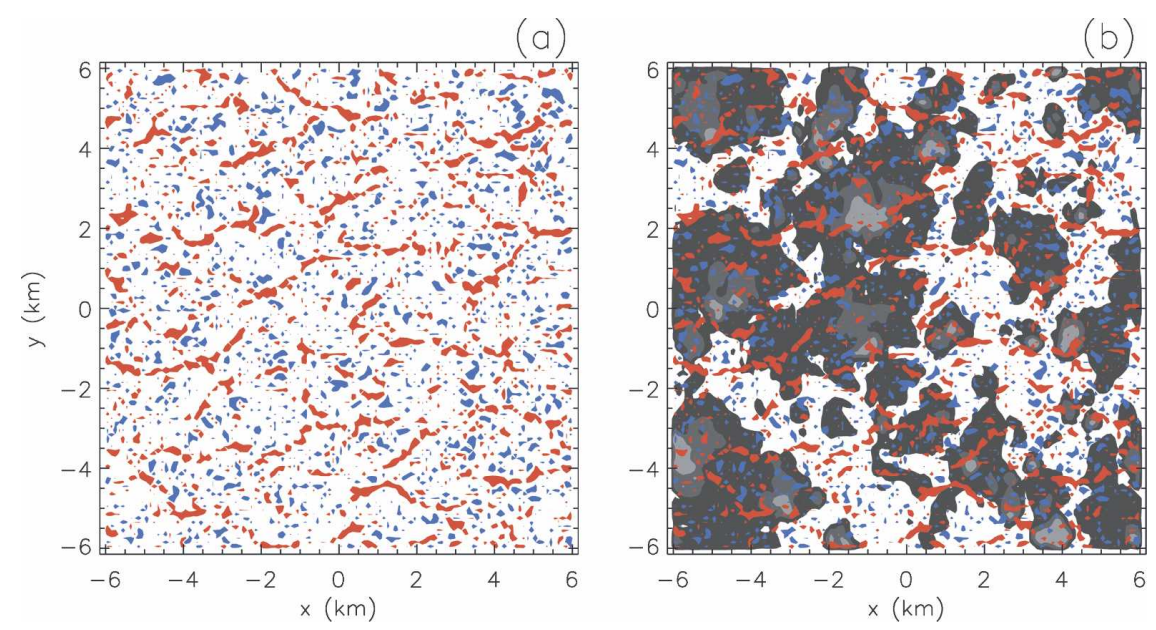

FIG. 10. Snapshots of the flow structure for $N_{a}=100 \mathrm{mg}^{-1}$ and $12.4 \mathrm{~km} \times 12.4 \mathrm{~km}$ domain size at time $t=3 \mathrm{~h} 30 \mathrm{~min}$. Superimposed on the near surface $(z=60 \mathrm{~m})$ divergenceconvergence fields are (a) surface precipitation rate and (b) LWP. Contours and shadings are the same as in Fig. 7.

ous than the $25 \mathrm{mg}^{-1}$ clouds (Table 2). The net effect is an increase in cloud fraction (Fig. 2a).

\section{Conclusions}

This large eddy simulation study of trade cumulus shows, as expected, a clear suppression of precipitation with increasing aerosol, but there are conflicting results for aerosol effects on cloud fraction and LWP. Aerosol tends to increase cloud fraction when $N_{a}$ increases from 25 to $100 \mathrm{mg}^{-1}$. However, further increases in $N_{a}$ lead to a decrease in cloud fraction probably due to the faster evaporation of the smaller cloud droplets, as discussed in Wang et al. (2003) and Xue and Feingold (2006). (The details of this evaporation-entrainment feedback and the ability of LES to resolve the details of the feedback are currently under investigation.) Thus, one might consider the following two different regimes for aerosol effects on the cloud life cycle: first, the precipitating regime, where increases in aerosol increase the residence time of cloud condensate; and a second non- or weakly precipitating regime, where increases in aerosol reduce the residence time of condensate through enhanced evaporation. While one might expect the balance of the precipitation effect and the thermal inertia effect to influence the cloud life cycle, we find, as in Jiang et al. (2006), no effect of aerosol on the mean lifetime of individual cells. This suggests that cloud fraction changes are manifested in changes in convective frequency, or changes in the size of individual clouds. Analysis shows that the simulated clouds decrease in size as aerosol increases from 25 to 100 $\mathrm{mg}^{-1}$. However, the clouds also become more numerous (indicating an increase in convective frequency), such that on balance, cloud fraction is positively correlated with aerosol over this range. Assuming that aerosol does not affect cloud lifetime over an even broader range of aerosol conditions (as in Jiang et al. 2006) suggests that the faster evaporation times associated with more polluted clouds will begin to dominate any

TABle 2. Comparison of mean and standard deviation of the lifetime of individual cloud cells for the $N_{a}=25 \mathrm{mg}^{-1}$ and $N_{a}=$ $100 \mathrm{mg}^{-1}$ cases over the $12.4 \mathrm{~km} \times 12.4 \mathrm{~km}$ domain. Results are considered for different ranges of cloud lifetime, as indicated at left. A comparison of the number of clouds in each category is also included.

\begin{tabular}{|c|c|c|c|c|c|c|}
\hline \multirow{2}{*}{$\begin{array}{l}\text { Range of lifetime } \\
\qquad(\min )\end{array}$} & \multicolumn{2}{|c|}{ No. of clouds } & \multicolumn{2}{|c|}{ Mean lifetime (min) } & \multicolumn{2}{|c|}{ Std dev (min) } \\
\hline & $25 \mathrm{mg}^{-1}$ & $100 \mathrm{mg}^{-1}$ & $25 \mathrm{mg}^{-1}$ & $100 \mathrm{mg}^{-1}$ & $25 \mathrm{mg}^{-1}$ & $100 \mathrm{mg}^{-1}$ \\
\hline $10-19$ & 102 & 178 & 13.8 & 13.9 & 2.5 & 2.9 \\
\hline $20-29$ & 33 & 74 & 23.7 & 23.7 & 3.1 & 2.9 \\
\hline $30-39$ & 14 & 34 & 34.7 & 33.4 & 3.4 & 2.9 \\
\hline $40-49$ & 10 & 12 & 43.6 & 43.4 & 3.0 & 3.2 \\
\hline $50-60$ & 1 & 5 & 57.0 & 57.4 & 0.0 & 2.6 \\
\hline $10-60$ & 160 & 303 & 19.8 & 20.4 & 9.8 & 9.9 \\
\hline
\end{tabular}


increases in convective frequency, and result in the lower simulated cloud fractions at increasingly higher aerosol mixing ratios (Fig. 2a).

The large eddy simulations show that precipitation promotes the development of open cells through a precipitation-dynamics feedback. In the middle of a precipitating cell, air motions are downward and hence divergent at the surface. At the edges of these cells, air motions are upward and convergent, leading to the formation of new convective clouds, some of which evolve into new zones of precipitation. These new precipitating events, in turn, generate divergent zones. Divergent regions are shown to be cooler and drier than the convergent zones near the surface. This loose network of open cells in trade wind cumuli is similar to the precipitating open cell or rift regions in broken stratocumulus.

It is noted that the aerosol concentration at which sufficient precipitation occurs for open cellular structure to develop is rather low. It is likely that this parameter varies considerably for different meteorological (and perhaps model configuration, i.e., grid-mesh size) conditions, because to first order both cloud water content and drop concentration determine precipitation formation. This warrants further study of the conditions and mechanisms under which open cellular structure occurs.

The dynamic response to precipitation and its induced downdrafts/outflow is proposed as a mechanism for the formation and evolution of open cellular structure. When precipitation is suppressed by aerosol, there is no obvious organization of the cloud fields. The evolution of the open cells studied here with LES show remarkable similarity to a time series of GOES visible satellite imagery of evolving cellular structure, albeit at different spatial scales, and suggests that precipitation plays an important role in organizing patterns of cloudiness.

Although key processes associated with open cell convection have been identified, it is not understood why the cellular structure is often maintained for several days, as observed from the satellites for POCs or rifts. Whether the succession of precipitating events, or a broader mesoscale forcing, is responsible for the long lifetime of the cellular structure requires further study with larger-scale models and longer simulations.

Acknowledgments. Huiwen Xue acknowledges support from a National Research Council postdoctoral fellowship. HX and GF thank NOAA's Climate Goal and NASA for supporting this study. HX also acknowledges support from Chinese NSF Grant 40675004. BS acknowledges support from NSF Grant ATM-0336849. We thank Margaret LeMone for directing our attention to the evolution of cell-like structures in the RICO satellite imagery.

\section{REFERENCES}

Ackerman, A. S., M. P. Kirkpatrick, D. E. Stevens, and O. B. Toon, 2004: The impact of humidity above stratiform clouds on indirect aerosol climate forcing. Nature, 432, 1014-1017.

Albrecht, B. A., 1989: Aerosols, cloud microphysics, and fractional cloudiness. Science, 245, 1227-1230.

Comstock, K. K., C. S. Bretherton, and S. E. Yuter, 2005: Mesoscale variability and drizzle in southeast Pacific stratocumulus. J. Atmos. Sci., 62, 3792-3807.

Feingold, G., B. Stevens, W. R. Cotton, and A. S. Frisch, 1996: The relationship between drop in-cloud residence time and drizzle production in numerically simulated stratocumulus clouds. J. Atmos. Sci., 53, 1108-1122.

Jiang, H., and G. Feingold, 2006: Effect of aerosol on warm convective clouds: Aerosol-cloud-surface flux feedbacks in a new coupled large eddy model. J. Geophys. Res., 111, D01202, doi:10.1029/2005JD006138.

— , H. Xue, A. Teller, G. Feingold, and Z. Levin, 2006: Aerosol effects on the lifetime of shallow cumulus. Geophys. Res. Lett., 33, L14806, doi:10.1029/2006GL026024.

Kogan, Y. L., 2006: Large-eddy simulation of air parcels in stratocumulus clouds: Time scales and spatial variability. $J$. Atmos. Sci., 63, 952-967.

Neggers, R. A. J., B. Stevens, and J. D. Neelin, 2006: A simple equilibrium model for shallow cumulus convection. Theor. Comput. Fluid Dyn., 20, 305-322.

Petters, M. D., J. Snider, B. Stevens, G. Vali, I. Faloona, and L. Russell, 2006: Accumulation mode aerosol, pockets of open cells, and particle nucleation in the remote subtropical Pacific marine boundary layer. J. Geophys. Res., 111, D02206, doi:10.1029/2004JD005694.

Pincus, R., and M. B. Baker, 1994: Effect of precipitation on the albedo susceptibility of clouds in the marine boundary layer. Nature, 372, 250-252.

Rauber, R. M., and Coauthors, 2007: Rain in shallow Cumulus over the Ocean-The RICO Campaign. Bull. Amer. Meteor. Soc., 88, 1912-1928.

Savic-Jovcic, V., and B. Stevens, 2008: The structure and mesoscale organization of precipitating stratocumulus. J. Atmos. Sci., in press.

Sharon, T. M., B. A. Albrecht, H. H. Jonsson, P. Minnis, M. M. Khaiyer, T. M. van Reken, J. Seinfeld, and R. Flagan, 2006: Aerosol and cloud microphysical characteristics of rifts and gradients in marine stratocumulus clouds. J. Atmos. Sci., 63, 983-997.

Stevens, B., 2007: On the growth of layers of nonprecipitating cumulus convection. J. Atmos. Sci., 64, 2916-2931.

_ , G. Feingold, R. L. Walko, and W. R. Cotton, 1996: Elements of the microphysical structure of numerically simulated nonprecipitating stratocumulus. J. Atmos. Sci., 53, 980 1006.

— W. R. Cotton, G. Feingold, and C.-H. Moeng, 1998: Large- 
eddy simulations of strongly precipitating, shallow, stratocumulus-topped boundary layers. J. Atmos. Sci., 55, 3616-3638.

— C.-H. Moeng, and P. P. Sullivan, 1999: Large-eddy simulations of radiatively driven convection: Sensitivities to the representation of small scales. J. Atmos. Sci., 56, 3963-3984.

— der a strong inversion. J. Atmos. Sci., 58, 1870-1891.

- , and Coauthors, 2005: Pockets of open cells and drizzle in marine stratocumulus. Bull. Amer. Meteor. Soc., 86, 51-57.

Stevens, D., A. S. Ackerman, and C. S. Bretherton, 2002: Effects of domain size and numerical resolution on the simulation of shallow cumulus convection. J. Atmos. Sci., 59, 3285-3301.
Twomey, S., 1974: Pollution and the planetary albedo. Atmos. Environ., 8, 1251-1256.

vanZanten, M. C., and B. Stevens, 2005: Observations of the structure of heavily precipitating marine stratocumulus. J. Atmos. Sci., 62, 4327-4342.

Wang, S., Q. Wang, and G. Feingold, 2003: Turbulence, condensation, and liquid water transport in numerically simulated nonprecipitating stratocumulus clouds. J. Atmos. Sci., 60, 262-278.

Xue, H., and G. Feingold, 2006: Large-eddy simulations of trade wind cumuli: Investigation of aerosol indirect effects. J. Atmos. Sci., 63, 1605-1622. 